ECCOMAS

Proceedia
COMPDYN 2021

$8^{\text {th }}$ ECCOMAS Thematic Conference on Computational Methods in Structural Dynamics and Earthquake Engineering

M. Papadrakakis, M. Fragiadakis (eds.) Streamed from Athens, Greece, 28 - 30 June 2021

\title{
EXPERIMENTAL \& NUMERICAL INVESTIGATION OF LAP-SPLICED R/C COLUMNS UNDER THREE POINT BENDING \& AXIAL COMPRESSION
}

\author{
Pelagia Kastiza ${ }^{1}$, Lazaros Melidis ${ }^{2}$, and Kostas Katakalos ${ }^{3}$ \\ 1,2,3 Lab. Strength of Materials and Structures, Aristotle University \\ peggykast12@gmail.com,1nmelidis@civil.auth.gr,kkatakal@civil.auth.gr
}

\begin{abstract}
There is a valuable research work around the strength capacity of lap spliced rebars in columns specifically in accordance with bond-slip behavior or column's seismic response. Nonetheless, lap splicing of rebars with anchored ends under combined bending and compressive loads has not yet been fully explored with due consideration of its components. It is imperative to investigate a column's behavior under bending for different levels of axial load ratio and with different reinforcing configurations employing either plain or ribbed steel bars. This paper comparatively demonstrates the results of experimental and non-linear numerical simulations pertaining to the effect of splice strength and anchoring on the compression lap splicing of rebars in concrete column. The experimental specimens are composed by prototypescale square columns with dense or sparse stirrups, measuring $250 \times 250 \mathrm{~mm}$ and $2000 \mathrm{~mm}$ in length, while the steel reinforcement includes a lap splice length of $400 \mathrm{~mm}$. Some of the tested specimens were reinforced with plain spliced bars with anchored ends; while others included ribbed spliced bars with free ends. All the specimens were tested under simultaneous bending and constant concentric, axial loading of $v=0.1$. Finally, the investigation results outline the influence of lap splice to the structural integrity of the column as a part of a composite system and generally evaluate the resistance of the lap splices in a plastic joint area, under parametric analysis.
\end{abstract}

Keywords: column, lap-splices, non-linear parametric analysis, plastic joint, three points bending, axial load ratio

ISSN:2623-3347 (C) 2021 The Authors. Published by Eccomas Proceedia.

Peer-review under responsibility of the organizing committee of COMPDYN 2021.

doi: $10.7712 / 120121.8684 .19498$ 


\section{INTRODUCTION}

In multistorey buildings, the columns of every single storey bear different levels of axial loading because of the scaled weight of the overhead storeys and it would be ideal if each of the column's longitudinal rebars could be placed as one single piece throughout the structure's entire height. This however cannot be accomplished in many cases for practical reasons and indicates the necessity of lap splices. Straight lap splices are employed in reinforced concrete to transfer loads from one steel reinforcing bar to another through the bonding between the embedding concrete and the two bars along a lapped length. Moreover, it is convenient to lengthen the steel bar via lap splice in a variety of cases, but when lapping steel bars from successive stories, it is essential to ensure the correct transmission of forces from the rebars of the superjacent floor to the rebars of the subjacent floor. This can be achieved by welding; however, this method has a few technical difficulties and it is used only in special occasions. As a result, the practice usually followed is the rebar lap-splicing as for instance with the help of anchorage hooks in the lap splice ends. ([1], [2]) As long as the cooperation between concrete and lap-spliced rebars is ensured and during the column's loading combination of bending and axial loading, the spliced bars interact with each other, following a complex force transfer mechanism, unlike the behavior of the individual ones. As a result, three stages of stresses development arise as shown in fig.1. Experimental studies have shown, however, that the bond slip behavior (associated with either splitting or pullout) in a lap splice region is similar to that of individual embedded bars and it is generally accepted that there is a small deviation between the load-carrying capacity of lap-spliced rebars and an individual bar.([1],[3]) A critical issue is when lap splices are located at potential plastic hinge regions and it is essential to study the factors which influence the structural integrity of those columns. This paper focuses on different parameters affecting the bearing capacity of $\mathrm{R} / \mathrm{C}$ columns. The rebars type, the presence of internal anchorages (hooks) and the stirrups density for a stable interface stiffness coefficient are investigated. The steel-concrete interface properties are formed under the scope of the CEBFIB bond stress-slip behavior pattern while the models include longitudinal reinforcement with ribbed or smooth bars, dense or sparse stirrups. ([4], [5])

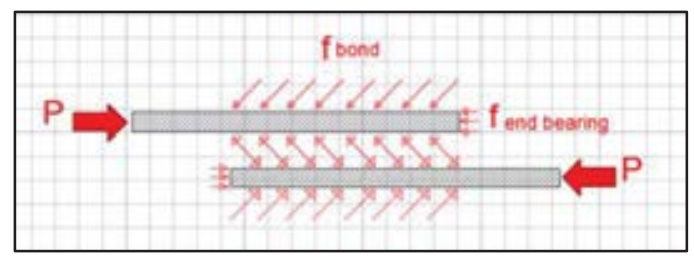

Figure 1: Components of compression lap spliced bars inside a column

\section{GEOMETRY OF SPECIMENS \& MATERIAL PROPERTIES}

The column specimens include longitudinal reinforcement of eight steel bars (plain and ribbed) of $\Phi 12 \mathrm{~mm}$ diameter, four for every side of the column due to the lap splice of the rebars, while there is also a transverse reinforcement of $\Phi 8$ steel stirrups. The nominal yield stress value of steel occurred from the experimental process of tension of a steel rebar equal to fy=549MPa. The Young's modulus of the steel is $200000 \mathrm{MPa}$ and the Poisson's ratio is 0.3. The reinforcement includes straight lap splices, which are employed in reinforced concrete to transfer loads from one steel reinforcing bar to another by bond between the embedding concrete and the two bars along the overlap length of $\mathrm{Lb}, \mathrm{t}=33 \mathrm{Db}=400 \mathrm{~mm}$. The compressive strength of concrete is given in terms of the characteristic compressive strength of $150 \mathrm{~mm}$ size cubes tested at 28 days (fck) and is equal to $20 \mathrm{MPa}$. The result has been derived from the 
laboratory experimental process of the compression of three, cubic, concrete specimens. As far as the steel concrete interface operation is concerned, a bond-slip model is used to assess the anchorage capacity of a bar. The bond failure pattern follows the three stages of CEB-FIB proposed model and it is schematically represented in Fig.2. Its failure is characterized by the initiation and propagation of cracks in the concrete-steel interface. [2]

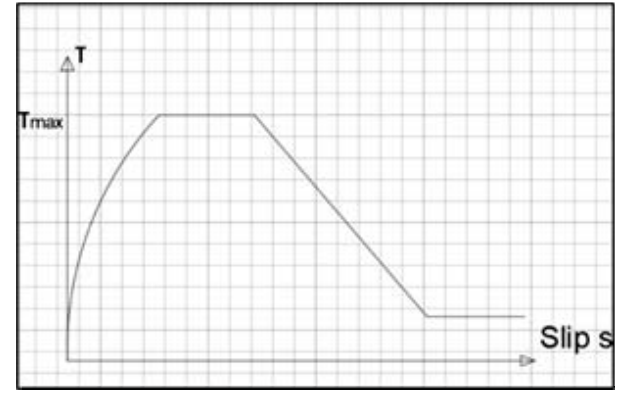

Figure 2: Bond-slip behavior relationship

\begin{tabular}{ll}
\hline $\begin{array}{l}\text { Concrete } \\
\text { Compressive strength fck }\end{array}$ & $20 \mathrm{MPa}$ \\
\hline Reinforcing steel bars & \\
\hline Yield stress fy & $549 \mathrm{MPa}$ \\
Ultimate stress fu & $672 \mathrm{MPa}$ \\
Ultimate strain $\mathrm{eu}$ & 0.10 \\
\hline
\end{tabular}

Table 1: Column specimens' structural identity

The investigation refers to a column part of a square cross section of $25 \times 25 \mathrm{~cm}$, which constitutes a member of a bigger and more complex columns-plate system. Specifically, the investigation area is a two meters region between two columns, interrupted by an integrated slab, including a lap splice length of $400 \mathrm{~mm}$, starting from the middle of the slab $(50 \mathrm{~cm}$ away from the inferior and $125 \mathrm{~cm}$ from the superior support, respectively). One half of the tested column specimens included longitudinal reinforcement of plain rebars with anchored ends sparse or dense stirrups, while the other half included ribbed rebars with free ends, with sparse or dense stirrups. The specimens were subjected to a loading combination of a three point bending, and a constant, axial loading equal to the first floor weight. The bending load was applied as horizontal displacement through a jack and was imposed in the inferior end of the lap spliced rebars, just in the middle of the bottom slab. What follows is the experimental and numerical investigation of the loading combination effects on the column specimens.

\section{EXPERIMENTAL INVESTIGATION \& RESULTS}

The laboratory experimental process included the test of eight column specimens of a prototype-scale, by being placed in a laboratory experimental setup with maximum loading capacity of 600tn. The specimens were subjected to a three-point bending with a simultaneous axial, concentric loading which was kept constant during the test. Specifically, two actuators were installed on the top and bottom of a column specimen so as to impose the axial load and one hydraulic jack was placed vertically at the bottom end of the lap spliced rebars of the column specimen, to apply a constant displacement throughout the test, on an area of the column where a plastic hinge was going to form. That displacement represents the horizontal force that column accepts by the bottom slab. The tested column specimens developed similar failure modes. [6]

The vertical load - displacement experimental results show that the presence of plus stirrups in the specimens with plain rebars, did not significantly ameliorate the structural correspondence of the specimen, while the presence of the axial loading lead to the rise of the load capacity of the column up to $30 \mathrm{kN}$ and the displacement of the area of interest was increased by $2 \mathrm{~mm}$, while the widen of the cracking in the vulnerable areas of the lap splice was mitigated. [7] 


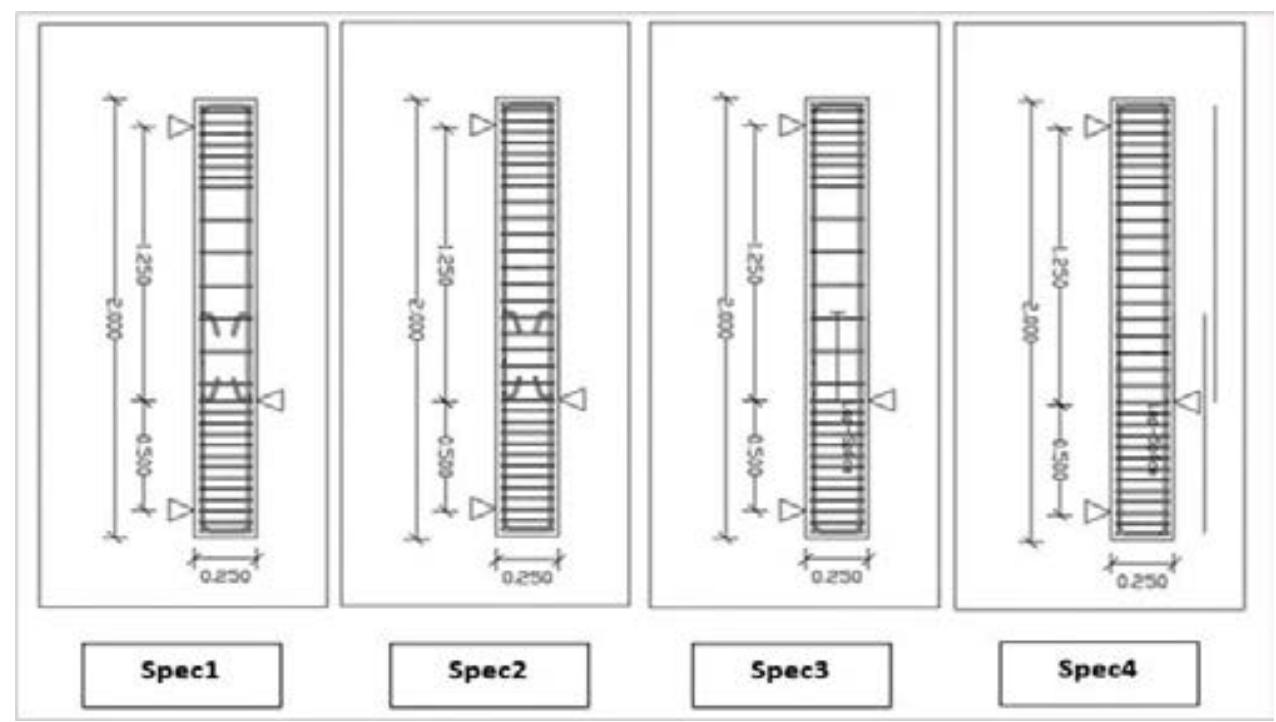

Figure 3: The geometry of the tested specimens

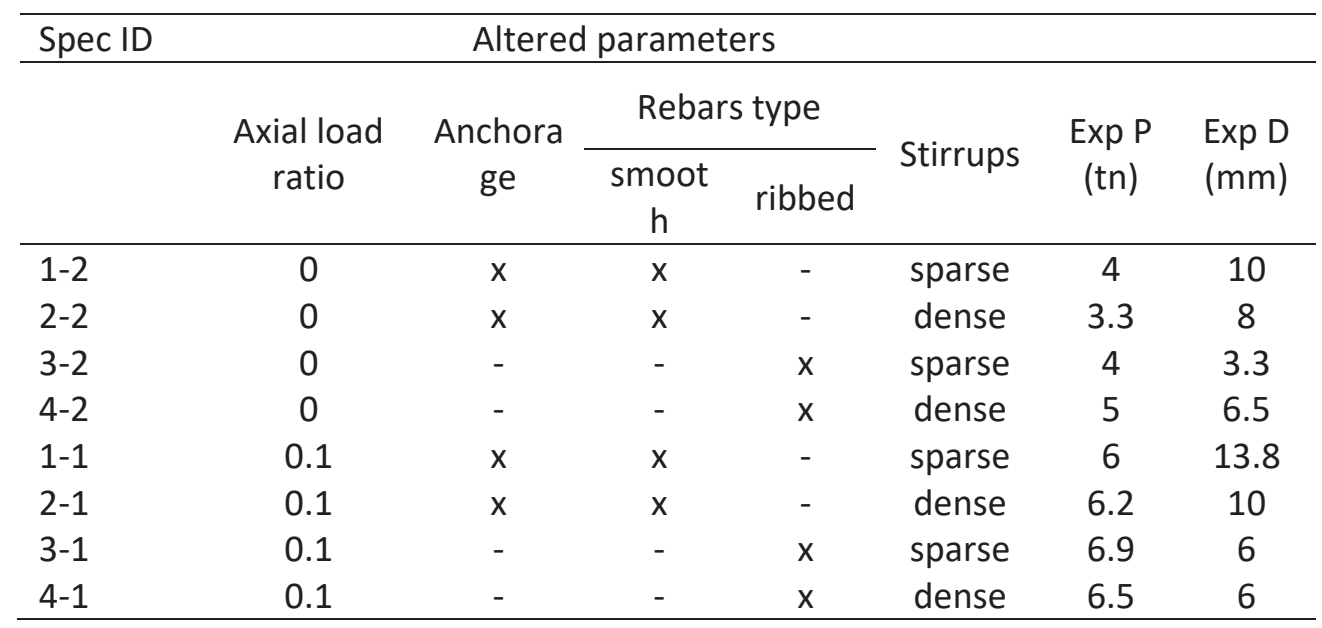

Table 2: Experimental results of the 8 specimens tested
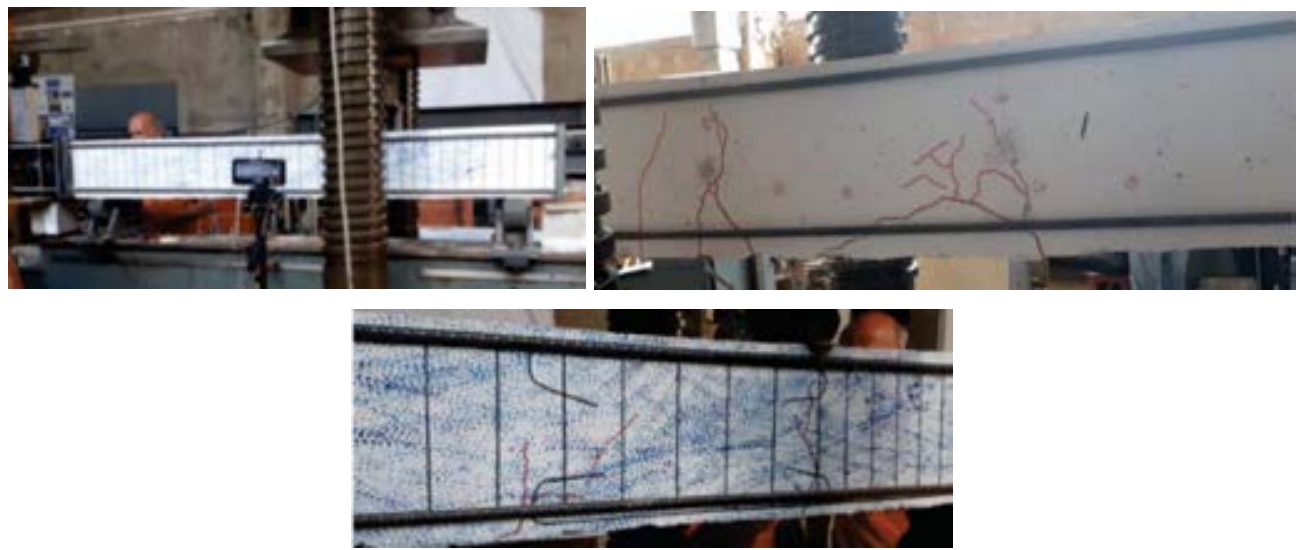

Figures 4,5,6: (left) The column specimen placed on the experimental setup of 600tn, subjected to 3 points bending through an imposed displacement by the vertical piston and axial loading of 70kN. (right): Regions of column's specimen failure -small-scale cracks (optics No.1). (bottom): Regions of local cracking at the anchoring regions of lap splices ends (optics No.2) 

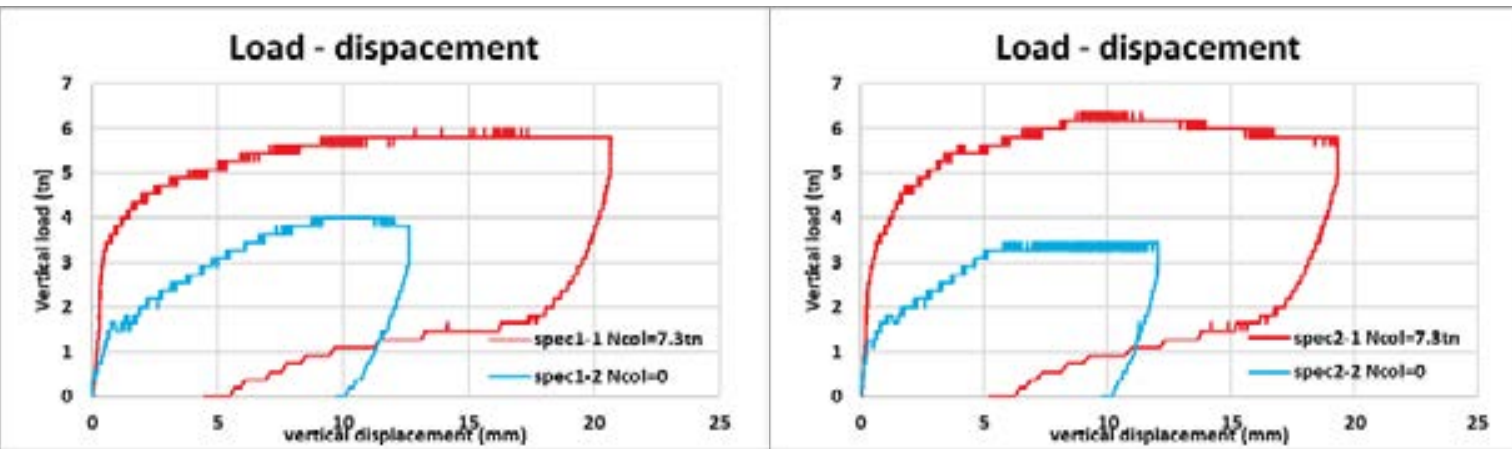

Figure 7: The comparison of the experimental results of column specimens with sparse (on the left) and dense stirrups (on the right) under axial loading case of $\mathrm{N}=0$ and $\mathrm{N}=70 \mathrm{kN}$

\section{NUMERICAL SIMULATION \& RESULTS}

\subsection{Simulation of the column model}

The presented modeling approach utilizes all the geometrical and mechanical properties described above (section 2). A detailed modeling is used. Concrete and longitudinal rebars are represented with 3D finite elements assigned with a Concrete Damaged Plasticity constitutive law and an elasto-plastic constitutive law respectively. Stirrups are simulated using wire elements and elasto-plastic material law. Between concrete and longitudinal rebars a cohesive - friction behavior (see figure 2), while stirrups is assumed to be perfectly embodied into the concrete. Two different models are investigated. The first one represents column with plain bars and anchors at rebars edges and the second one with free edges simulating the column reinforced with ribbed rebars. Additionally, different bonding strength between concrete and steel bars is given. The relatively poor bond strength between concrete and smooth rebars is given $1 \mathrm{MPa}$, while the bond strength between concrete and ribbed rebars is given 5MPa. Below all numerical predictions carried out are listed together with the reinforcing detail and the column's axial compressive load (table 3 ).

\begin{tabular}{|c|c|c|c|c|c|c|c|c|c|}
\hline \multirow[t]{2}{*}{$\begin{array}{c}\text { Specimen } \\
\text { ID }\end{array}$} & \multicolumn{5}{|c|}{ Altered parameters } & \multicolumn{2}{|c|}{$\begin{array}{l}\text { Load capacity } \\
\text { (tn) }\end{array}$} & \multicolumn{2}{|c|}{$\begin{array}{c}\text { Displacement } \\
\text { range (mm) }\end{array}$} \\
\hline & $\begin{array}{l}\text { Axial load } \\
\text { ratio }\end{array}$ & $\begin{array}{l}\text { Anchorage } \\
\text { presence }\end{array}$ & Rebars & type & $\begin{array}{l}\text { Stirrups } \\
\text { presence }\end{array}$ & $\begin{array}{c}\text { Exp } \\
P\end{array}$ & Num $P$ & $\operatorname{Exp} D$ & Num D \\
\hline & & & smooth & ribbed & & & & & \\
\hline $1-2$ & 0 & $x$ & $x$ & - & sparse & 4 & 4.1 & 10 & 14.6 \\
\hline $2-2$ & 0 & $x$ & $x$ & - & dense & 3.3 & 4.3 & 8 & 15.5 \\
\hline $3-2$ & 0 & - & - & $x$ & sparse & 4 & 4.1 & 3.3 & 3.3 \\
\hline $4-2$ & 0 & - & - & $x$ & dense & 5 & 3.8 & 6.5 & 3 \\
\hline $1-1$ & 0.1 & $x$ & $x$ & - & sparse & 6 & 5.6 & 13.8 & 14.14 \\
\hline $2-1$ & 0.1 & $x$ & $x$ & - & dense & 6.2 & 5.8 & 10 & 14.75 \\
\hline $3-1$ & 0.1 & - & - & $x$ & sparse & 6.9 & 5.5 & 6 & 3.8 \\
\hline $4-1$ & 0.1 & - & - & $x$ & dense & 6.5 & 5.1 & 6 & 3.9 \\
\hline
\end{tabular}

Table 3: Specimens' description with the experimental \& numerical results 


\subsection{Numerical results investigation}
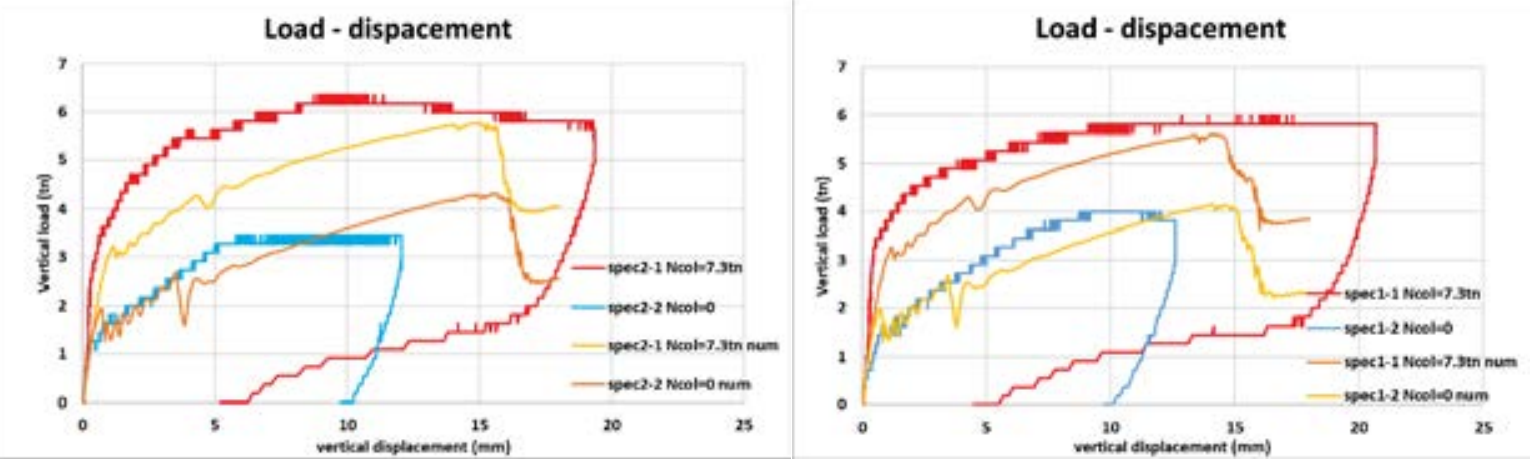

Figure 8: Plot of numerical results for $v=0 \& v=0.1$, of specs 2-1, 2-2 (left) and of specs 1-1, 1-2 (right)
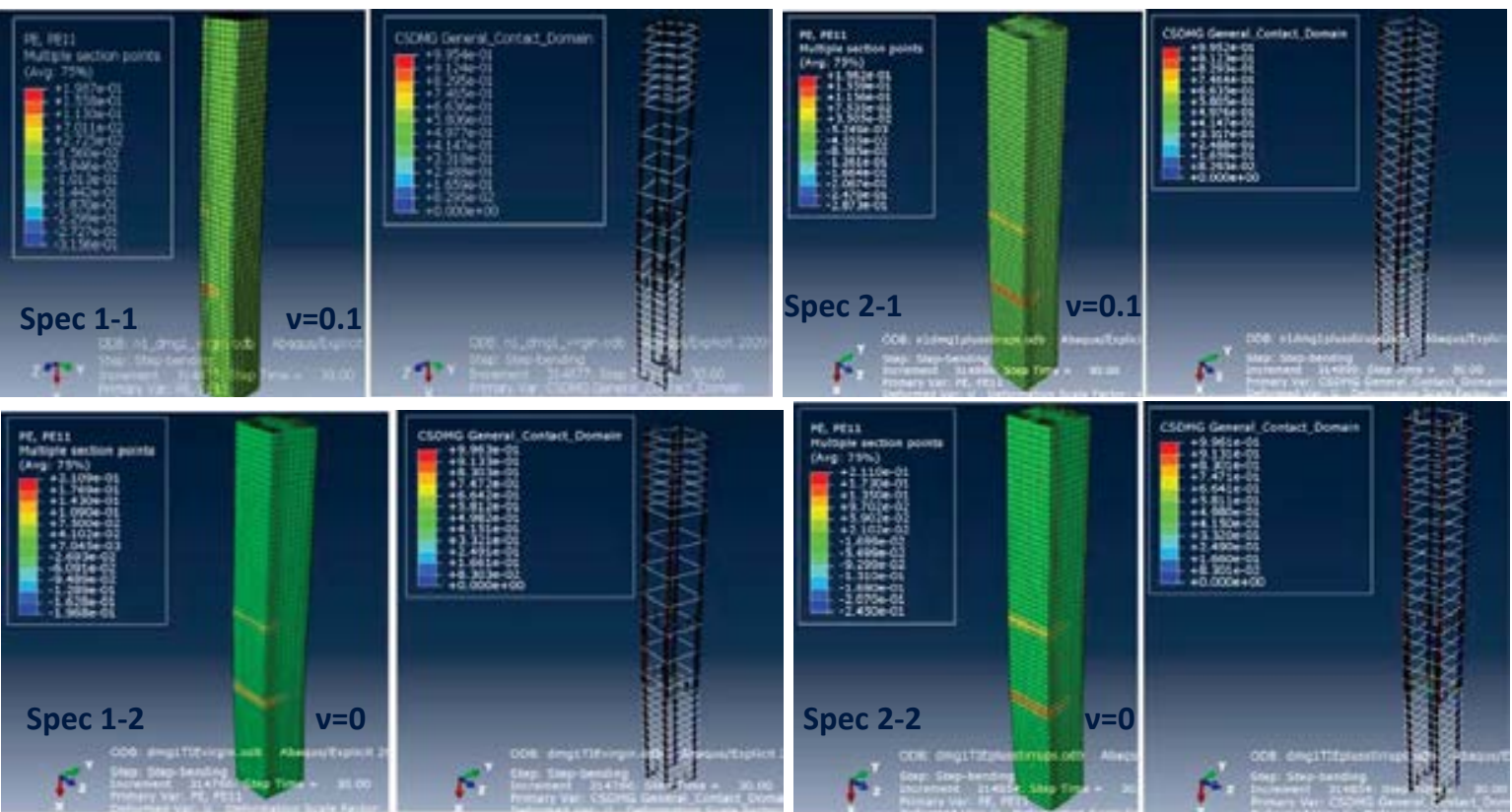

Figure 9: Failure modes: Plastic strains of concrete and CSDMG for specimens 1-1, 2-1 $(v=0.1) \& 1-2,2-2(v=0)$ with plain rebars and internal anchoring
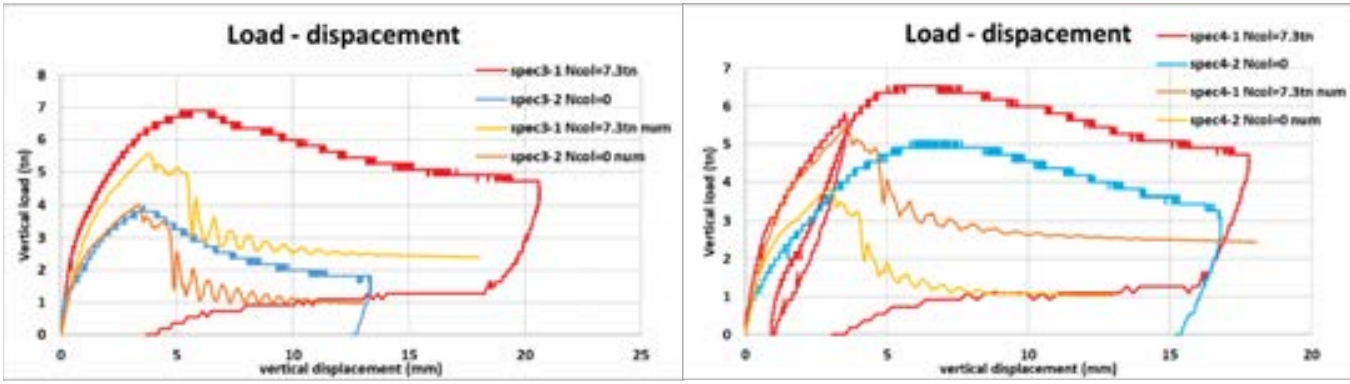

Figure 10: Plots of numerical results for $v=0 \& v=0.1$, of specs $3-1,3-2$ (left) and of specs 4-1, 4-2 ( right) 


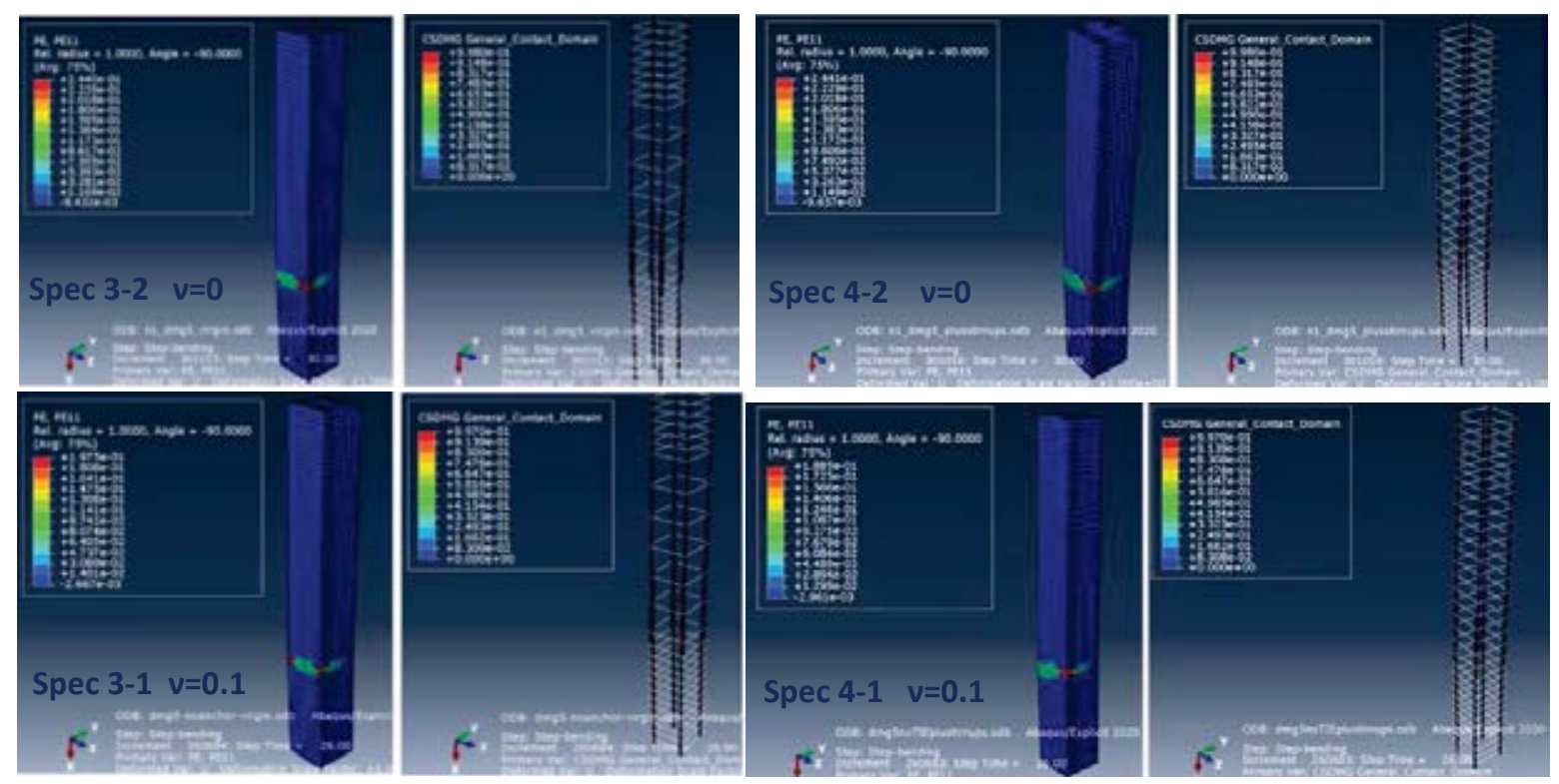

Figure 11: Failure modes: Plastic strains of concrete and CSDMG for specimens 3-2, 4-2 (v=0) \& 3-1, 4-1 $(v=0.1)$ with ribbed rebars

\section{- Numerical results evaluation}

\begin{tabular}{lccccccc}
\hline $\begin{array}{l}\text { Spec } \\
\text { ID }\end{array}$ & experimental results & \multicolumn{2}{c}{ numerical results } & \multicolumn{3}{c}{$\begin{array}{c}\text { exp-num deviation } \\
\text { rate }\end{array}$} \\
\hline & & & & & & \\
& $\mathrm{P}(\mathrm{tn})$ & $\mathrm{d}(\mathrm{mm})$ & $\mathrm{P}(\mathrm{tn})$ & $\mathrm{d}(\mathrm{mm})$ & $\mathrm{P}(\mathrm{tn})$ & $\mathrm{P}(\%)$ & $\mathrm{d}(\mathrm{mm})$ \\
\cline { 2 - 8 } $1-1$ & 6 & $8-13$ & 5.6 & 14 & 0.4 & 7.14 & $1-4$ \\
$1-2$ & 4 & $9-11$ & 4.1 & 14.6 & 0.1 & 2.5 & $3.6-5.6$ \\
$2-1$ & 6.2 & 10 & 5.8 & 14.8 & 0.4 & 6.9 & 4.8 \\
$2-2$ & 3.3 & $7-10$ & 4.3 & 15.5 & 1 & 30.3 & $5.5-8.5$ \\
$3-1$ & 6.9 & 6 & 5.5 & 4 & 1.4 & 25.5 & 2 \\
$3-2$ & 4.1 & 3.3 & 4.1 & 3.3 & 0 & 0 & 0 \\
$4-1$ & 6.5 & 6 & 5.1 & 4 & 1.4 & 27.5 & 2 \\
$4-2$ & 5 & 6.5 & 3.8 & 3 & 1.2 & 31.6 & 3.5 \\
\hline
\end{tabular}

Table 4: Validation of the numerical results

The maximum undertaken loads and displacements for the numerical investigation for $v=0$ and 0.1 lie between 3.8-5.8tn and 3-15.5mm respectively and are higher for the anchored specimens. There is also a satisfactory exploitation rate of the concrete's and steel's loadbearing capacity for the plain reinforced specimens as it is observed a strong anchorages' resistance which causes local damage to the concrete at the lap splice ends, the plot also shows delayed load drop and increased steel deformation and displacement. However, when the rebars are laid out freely without anchoring at the ends, the strength of the concrete steel interface is reinforced only by the interface bond between the surface of the rebar and the circumferential concrete. A premature load drop is observed for a smaller displacement due to the weak resistance of the steel ribs against anchors. It is concluded that the presence of anchors at the rebars' ends, contributes in a significant rate to the utilization of the bearing capacity of the individual materials, steel and concrete, prolonging increase in load intake and deformation for the specimen. The plastic deformation of the concrete and the steel stress at the anchors' areas 
are intensified due to the exceeding of the concrete tensile strength by the stress intensity of the surrounding steel.

\section{DISCUSSION ON THE INVESTIGATIONAL RESULTS}

A general convergence is observed between the experimental and the numerical results, included the failure modes. The same loading combination with displacement control was used in both experimental tests and numerical simulation. As far as the failure patterns are concerned, Fig. 12 compares the tensile damage nephogram obtained from the numerical simulation with the surface cracks obtained from the experimental test of the same specimen. The two failure modes are similar with extended cracks being concentrated on the bottom lap spliced end where the developed stress is higher for the ribbed reinforced specimens 3, 4. While, in the case of specimens 1 and 2, the cracking was developed on the concrete surface of both the anchored lap splice ends. According to the plots of the numerical and experimental results of undertaken load and displacement, a satisfactory convergence rate was achieved in the terms of the maximum load, the corresponding displacement, and the slope of the curves. (Table 5) In addition, the strength of the interface was simulated by realistic cohesion stresses and the expected forms of failure were induced. As a result, a reliable numerical tool has been developed and quantified so as to predict the response of critical $\mathrm{RC}$ members under the influence of various loading factors.
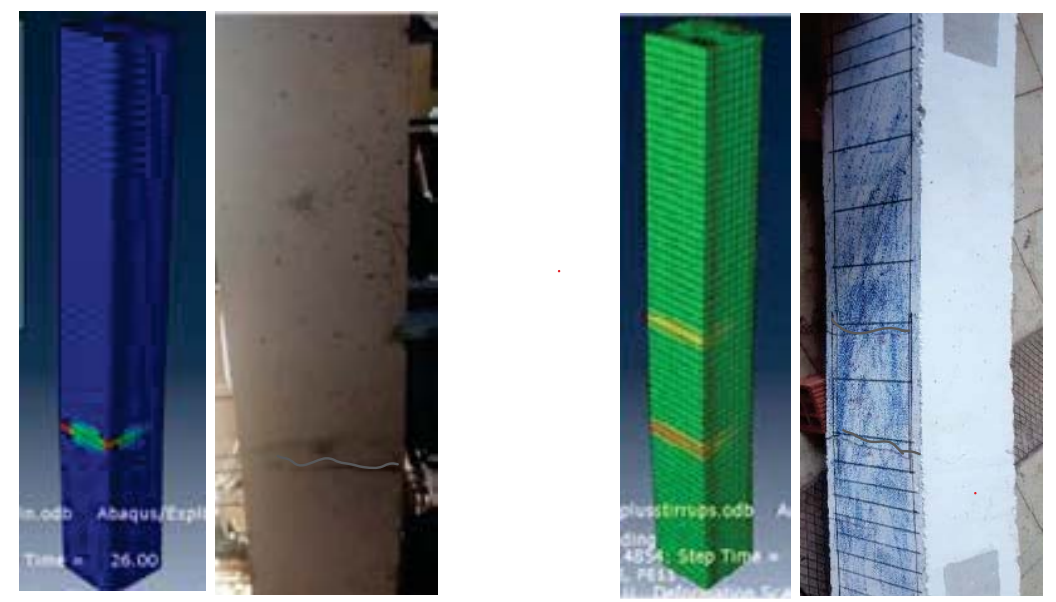

Figure 12: Comparison of the numerical and experimental failure modes of the ribbed (left) and plain with internal anchoring (right), reinforced specimens

\begin{tabular}{lccc}
\hline Spec ID & $\begin{array}{c}\text { Test } \\
\text { results (tn) }\end{array}$ & Simulation results (tn) & Convergence rate (\%) \\
\hline $1-2$ & 4 & 4.1 & 97.6 \\
$2-2$ & 3.3 & 4.3 & 76.7 \\
$3-2$ & 4 & 4.1 & 97.6 \\
$4-2$ & 5 & 3.8 & 76 \\
$1-1$ v1 & 6 & 5.6 & 93.3 \\
$2-1$ v1 & 6.2 & 5.8 & 93.6 \\
$3-1$ v1 & 6.9 & 5.5 & 79.7 \\
$4-1$ v1 & 6.5 & 5.1 & 78.5 \\
\hline
\end{tabular}

Table 5: Comparison of the ultimate undertaken load of column specimens for $v=0 \& v=0.1$ 


\section{CONCLUSIONS}

An experimental and a numerical study was performed on full scale RC column specimens to evaluate the behavior of lap splices as a part of a complex structural system under the load combo of three point bending and a constant compression on the edges. The type of longitudinal reinforcement, the presence of stirrups, the free and anchored ends of the lap spliced rebars and the magnitude of the load ratio, were the main parameters considered in this study. According to the tests results, including the global behavior of the splices and the failure modes that the column specimens develop, the major findings of this study are as follows:

- The absence of anchorage leads to the premature slip of the lap spliced rebars and to early load drop under the insufficient exploitation of the materials' properties.

- The presence of dense stirrups does not essentially contribute to the rise of the undertaken load but it reduces the deformation of the concrete, by restricting the opening of the surficial cracking.

- The proposed finite element model of Abaqus for RC column is in good agreement with the experimental results such as load carrying capacity, displacement, failure mode and CEBFIB bond stress-slip behavior pattern.

- The maximum undertaken load and the respective displacement are getting greater for both the plain and ribbed reinforced specimens as the axial load ratio rises from 0 to $7 \mathrm{tn}$.

- The main difference among the results for specimens with ribbed and plain rebars, is the fact that the absence of anchoring leads to early load drop and a low exploitation of material properties, as the slip of the ribbed rebars happens prematurely.

- The presence of the lap splice implies a failure mode connected with the slip of the reinforcing bars.

- The higher degree of failure in the column specimens, for both the numerical and experimental results, is located in the plastic joint area, on the bottom end of the lap splice length. 


\section{REFERENCES}

[1] S.P. Tastani, S. J. Pantazopoulou, Direct Tension Pullout Bond Test: Experimental Results, M.ASCE, Journal of Structural Engineering Vol. 136, Issue 6, 2010.

[2] Delso Juan Murcia, P. Benson Shing, Bond-Slip Model for Detailed Finite-Element Analysis of Reinforced Concrete Structures, M.ASCE, Journal of Structural Engineering Vol. 141, Issue 4, 2015.

[3] Dionysis Biskinis, Michael N. Fardis, Models for FRP-wrapped rectangular RC columns with continuous or lap-spliced bars under cyclic lateral loading, Engineering Structures Volume 57, Pages 199-212, 2013

[4] Luccioni, López, Danesi Bibiana María, Daniel Ernesto, Rodolfo Francisco, Bond-Slip in Reinforced Concrete Elements, Journal of Structural Engineering Vol. 131, Issue 11, 2005.

[5] Zanuy Carlos, Iván M. Díaz, Stress distribution and resistance of lap splices under fatigue loading, Engineering Structures Volume 175, Pages 700-710, 2018.

[6] M.A Najafgholipour, S.M Deghan, M.Khani, A. Heidari, The performance of lap splices in RC beams under inelastic reversed cyclic loading, Structures Volume 15, Pages 279-291, 2018.

[7] H.Kupfer, H.K Hilsdorf, H. Rusch, Biaxial strength of concrete, Journal of the American Concrete Institute, Vol.66, No.8, pp.656-666, 1969. 